University of South Carolina

Scholar Commons

Faculty Publications

Electrical Engineering, Department of

6-1-2009

\title{
A Miniature Implanted Inverted-F Antenna for GPS Application
}

Mohammed Z. Azad

Motorola, Inc., azad@motorola.com

Mohammod Ali

University of South Carolina - Columbia, alimo@engr.sc.edu

Follow this and additional works at: https://scholarcommons.sc.edu/elct_facpub

Part of the Electrical and Computer Engineering Commons

\section{Publication Info}

Published in IEEE Transactions on Antennas and Propagation, Volume 57, 2009, pages 1854-1858. http://ieeexplore.ieee.org/xpl/Recentlssue.jsp?punumber=8

(C) 2009 by IEEE

This Article is brought to you by the Electrical Engineering, Department of at Scholar Commons. It has been accepted for inclusion in Faculty Publications by an authorized administrator of Scholar Commons. For more information, please contact digres@mailbox.sc.edu. 
[8] A. J. Johansson, "Performance of a radio link between a base station and a medical implant utilizing the MICS standard," in Proc. 26th Annu. Int. Conf. Eng. in Med. Biol. Society, 2004, vol. 1, pp. $2113-2116$.

[9] M. Sun, M. Mickle, W. Liang, Q. Liu, and R. J. Sclabassi, "Data communication between brain implants and computer," IEEE Trans. Neural Syst. Rehab. Eng., vol. 11, no. 2, pp. 189-192, Jun. 2003.

[10] L. Roelens, S. Van den Bulcke, W. Joseph, G. Vermeeren, and L. Martens, "Path loss model for wireless narrowband communication above flat phantom," Electron. Lett., vol. 42, no. 1, pp. 10-11, Jan. 5, 2006.

\section{A Miniature Implanted Inverted-F Antenna for GPS Application}

\author{
Mohammed Z. Azad and Mohammod Ali
}

\begin{abstract}
A miniature implanted Hilbert inverted-F antenna design at the $1.575 \mathrm{GHz}$ global positioning system (GPS) frequency is proposed, which can be used to track the location of its user, e.g., the elderly with declining mental capacity (Alzheimer's disease). A detailed parametric study of the antenna design is performed by considering it to be implanted within a human muscle model. The effects of the substrate, superstrate, and the nearby muscle tissue on antenna performance are carefully investigated. A laboratory prototype of the antenna was built and tested within a muscle equivalent fluid indicating good VSWR performance. Finally the said antenna when placed within the tissue equivalent fluid was also tested to track GPS satellites with the help of a low noise amplifier (LNA). Such field measurements demonstrate that the antenna can easily lock into six or more satellites which are more than enough to determine the location of a person.
\end{abstract}

Index Terms-Global positioning system (GPS), Hilbert, implanted, inverted-F antenna (IFA).

\section{INTRODUCTION}

The growth and proliferation of wireless communications can be felt in almost every aspect of our lives. Apart from mobile telephony, wireless local area network (WLAN), and Bluetooth recently attention is also being placed on implantable wireless applications. Antenna design for implantable or biomedical applications is an interesting and challenging task. Examples of antennas encompassing a broad area of biomedical applications include cardiac ablation [1], biomedical telemetry [2], data telemetry for retinal prosthesis [3] and the treatment of different diseases using hyperthermia [4]. Recently RFID

Manuscript received August 26, 2008; revised November 19, 2008. Current version published June 03, 2009. This work was supported in part by a National Science Foundation Career Award ECCS: 0237783

M. Z. Azad was with the University of South Carolina, Columbia, SC 29208, USA. He is now with Motorola, Inc., Sunrise, FL 33325 USA (e-mail: azad@motorola.com).

Mohammod Ali is with the Department of Electrical Engineering, University of South Carolina, Columbia, SC 29208 USA (e-mail: alimo@engr.sc.edu).

Color versions of one or more of the figures in this communication are available online at http://ieeexplore.ieee.org.

Digital Object Identifier 10.1109/TAP.2009.2016805 (radio frequency identification device) implants which can carry an identification number and history of a person have also been proposed [5]. Using an implanted RFID module medical caregivers can easily access important patient ID and data within a short period of time or even when the patient is unconscious. An implantable glucose-sensing RFID microchip named the Digital Angel has also been proposed which can sense and measure blood sugar [6].

Recently, we presented some preliminary results on the design of an implantable Global positioning system (GPS) antenna to track the elderly with declining mental capacity (Alzheimer's disease) [7]. Albeit one may envision a wearable wristband type GPS unit for the wearer such a unit is prone to breakage, damage or possible removal. An implantable GPS unit does not have those disadvantages. For GPS applications antenna research to date has mostly focused on external antennas, such as circularly polarized patches and quadrifilar helices. This of course does not include miniature linearly polarized embedded antennas that are integrated within today's mobile phones which employ base station assisted GPS technology. In terms of external GPS antennas an excellent comparison between microstrip patch, helical, and conical spiral antennas can be found in [8]. A quadrifilar helical antenna [9] placed on choke rings and patch antennas [10], [11] have also been proposed for GPS application. Recently an integrated GPS antenna was proposed for vehicular application [12].

For implantable application at the GPS frequency of $1.575 \mathrm{GHz}$ antenna gain will be extremely low due to the losses in the body tissue materials. Thus unless a highly directive antenna is implemented the implanted antenna alone will not be able to lock into the GPS satellites without a low noise amplifier (LNA). Implementing a highly directive GPS antenna is difficult if not impossible for this scenario because of the aperture size requirement. So it makes sense instead to design and use a miniaturized antenna with relatively low efficiency and then use an integrated LNA. Earlier researchers have shown that the Hilbert curve can be used to design miniaturized antennas [13]-[16] by dint of its longer current flow path within a specific surface area. In this communication an inverted-F antenna (IFA) is studied and designed using the Hilbert curve. The antenna geometry is similar to the one described in our earlier work [16]. To design the antenna for implanted application at the GPS frequency of $1.575 \mathrm{GHz}$ simulations were performed in $\mathrm{HFSS}^{1}$ and XFDTD 2 (with anatomically based human head and body model). A laboratory prototype of the GPS inverted-F antenna is then fabricated and measured for VSWR performance by immersing it within a muscle equivalent liquid. Finally, the said antenna when immersed in the liquid is connected to an LNA outside of the liquid and is used to perform field tests that demonstrate the ability or inability of locking into GPS satellites.

\section{ANTENNA DESIGN}

The simulation model of the proposed Hilbert IFA implanted under the skin and embedded within human muscle is shown in Fig. 1. Since the antenna must fit on the surface of a small battery pack the back side of the battery pack will serve as the ground plane for the antenna. Therefore we chose a $20 \mathrm{~mm}$ by $20 \mathrm{~mm}$ ground plane. The antenna including the ground plane was then embedded within a 40 by 40 by $15 \mathrm{~mm}^{3}$ muscle block, consisting of homogeneous $14 \mathrm{~mm}$ thick human muscle tissue $\left(\varepsilon_{\mathrm{r}}=54.7, \sigma=1.375 \mathrm{~S} / \mathrm{m}\right.$ at $\left.1.575 \mathrm{GHz}\right)$ and $1 \mathrm{~mm}$ thick homogeneous skin tissue $\left(\varepsilon_{\mathrm{r}}=38.9, \sigma=1.17 \mathrm{~S} / \mathrm{m}\right.$ at $1.575 \mathrm{GHz}$ ) [17]. The antenna depth, $d$ was kept fixed at $1 \mathrm{~mm}$. Thus the top surface of the antenna was $2 \mathrm{~mm}$ below the skin. The geometry

\footnotetext{
${ }^{1}$ Ansoft Corporation: www. hfss.com

${ }^{2}$ Remcom Corporation: www.remcom.com
} 

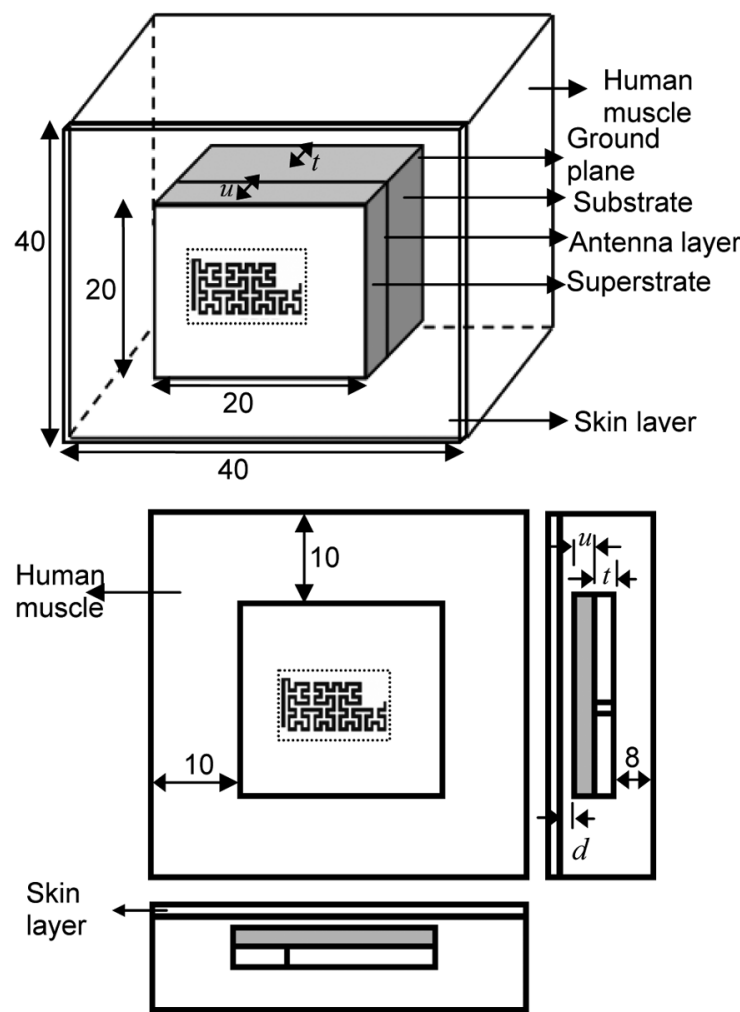

Fig. 1. Simulation model (all dimensions are in $\mathrm{mm}$ ).

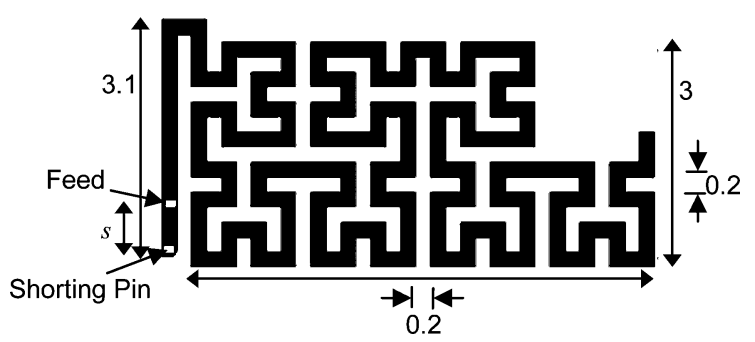

Fig. 2. Antenna geometry ( $\mathrm{mm})$ and approximate position under the skin of a person.

of the antenna can be seen in Fig. 2. This is a 4th iteration order Hilbert geometry.

In [18], it was noted that the performance of an antenna operating in the 402-405 MHz was similar whether implanted within a simple homogeneous model or within a complex real human body model. Therefore, for simplicity of analysis we chose to use a homogeneous muscle block to study the characteristics of this antenna. Subsequently we also used a relatively larger muscle block to analyze the antenna.

\section{RESULTS}

Computed VSWR data for the proposed implanted antenna $(u=$ $2 \mathrm{~mm}, t=2 \mathrm{~mm}$, and $d=1 \mathrm{~mm}$ ) are shown in Fig. 3. The feed position was kept fixed while the shorting pin was moved in order to change the distance, $s$. It is clear from Fig. 3 that by adjusting $s$ the impedance matching of the antenna can be controlled quite easily. Next, the antenna was simulated within a large muscle block instead of the one shown in Fig. 1. The muscle block shown in Fig. 1 was removed and a $170 \mathrm{~mm}$ by $170 \mathrm{~mm}$ by $63 \mathrm{~mm}$ muscle block was added. Comparing the dotted and the dashed traces which represent the small and the large muscle blocks respectively it is clear that there is a slight

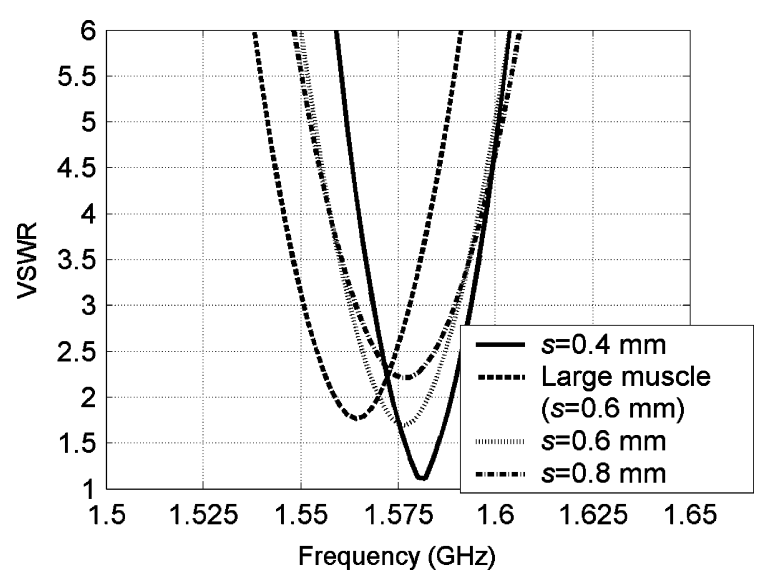

Fig. 3. Computed VSWR versus frequency: feed to shorting pin distance $s$ as a parameter.

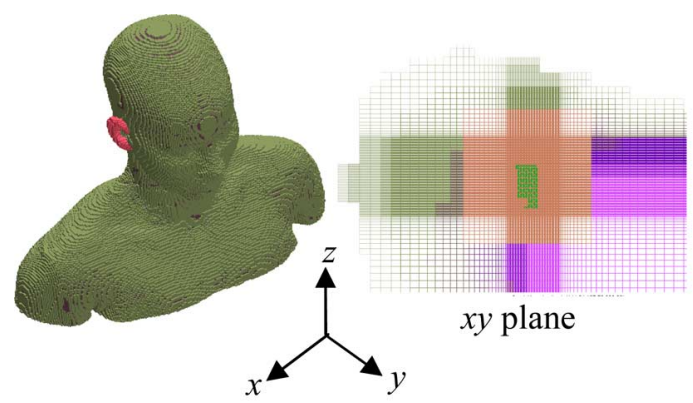

(a)

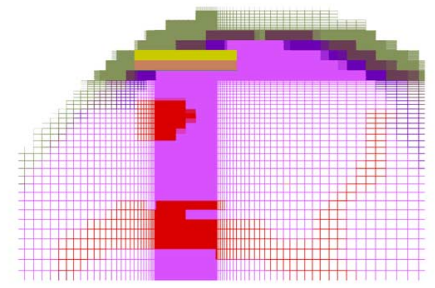

$y z$ plane

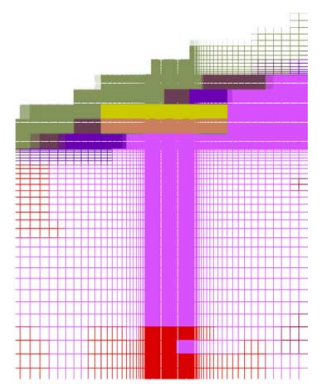

$x z$ plane (b)

Fig. 4. Anatomically based model in XFDTD with meshing in different planes (a) Anatomical model and (b) meshing.

reduction $(10 \mathrm{MHz})$ in the antenna resonant frequency with the large muscle block.

Finally we used an anatomically based human head and body model in XFDTD to investigate the antenna. We used the male model named Duke obtained from the ITIS Foundation [19]. The model was truncated and the head and the shoulder regions were kept. The model consisted of various tissue parameters the dielectric constant and conductivity values of which conform to the values listed in [17]. The Hilbert IFA was placed under the shoulder of the model. Since unlike the homogeneous block muscle model the anatomically based model had a shoulder with various slopes the antenna depth under the skin surface was not the same at all points of the antenna. The model and the meshing with the antenna are illustrated in Fig. 4. Three cases were considered based on cell size refinement. Case 1: Block muscle and skin model where $0.1 \mathrm{~mm}$ mesh size was used for a $10 \mathrm{~mm}$ by $10 \mathrm{~mm}$ by $8 \mathrm{~mm}$ cube surrounding the antenna and tissues while in the rest 


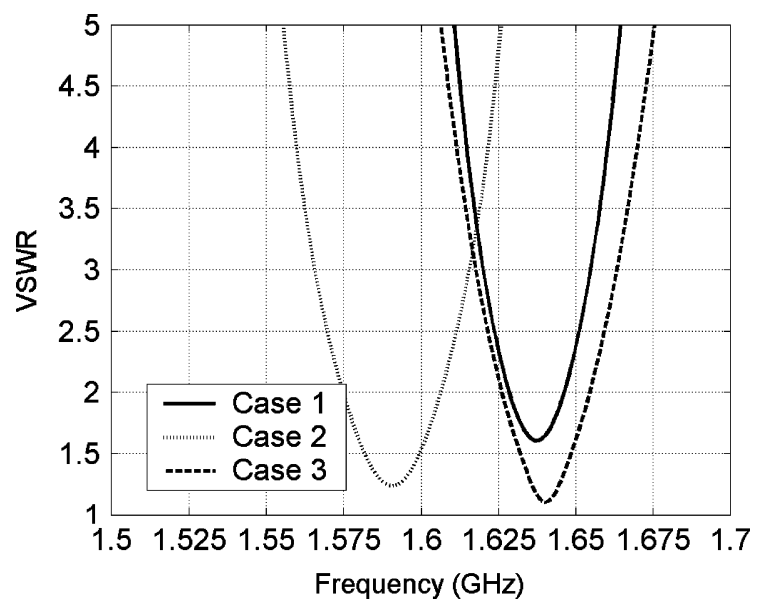

Fig. 5. Results of VSWR in XFDTD for muscle-skin block and anatomically based human head and body models.

of the model the mesh size was $2 \mathrm{~mm}$ by $2 \mathrm{~mm}$ by $1 \mathrm{~mm}$. The transition was not abrupt but an adaptive meshing was generated. Case 2: Block muscle and skin model where $0.05 \mathrm{~mm}$ mesh size was used for a $10 \mathrm{~mm}$ by $10 \mathrm{~mm}$ by $8 \mathrm{~mm}$ cube surrounding the antenna and tissues while in the rest of the model the mesh size was $2 \mathrm{~mm}$ by $2 \mathrm{~mm}$ by $1 \mathrm{~mm}$. Case 3: Anatomically based human head and body model where $0.1 \mathrm{~mm}$ mesh size was used for a $10 \mathrm{~mm}$ by $10 \mathrm{~mm}$ by $8 \mathrm{~mm}$ cube surrounding the antenna and tissues while in the rest of the model the mesh size was $5 \mathrm{~mm}$ by $5 \mathrm{~mm}$ by $2 \mathrm{~mm}$. Results of Cases 1, 2, and 3 are shown in Fig. 5. As apparent, for the block muscle and skin model using a finer discretization resulted in a lower resonant frequency which matches with our HFSS results. The simulation time taken for Case 3 was almost 2 days on a powerful desktop computer $(3.2 \mathrm{GHz}, 64$ bit quad core, and 8 GB RAM). The resonant frequency of the antenna for Cases 1 and 3 are nearly similar. Thus if further mesh refinement were done for Case 3 the antenna resonant frequency would most likely have matched with our HFSS results. Computed normalized radiation patterns at $1.585 \mathrm{GHz}$ and $1.635 \mathrm{GHz}$ are shown in Fig. 6 for the antennas implanted within the small muscle block and the anatomically based human head and body models, respectively. Peak gain for these two cases are $-18.9 \mathrm{dBi}$ and $-17.5 \mathrm{dBi}$ respectively. As expected the patterns within the anatomically based human head and body model show more shadowing due to the size of the implanting environment.

As apparent the antenna is dominant linearly polarized and the cross-polarization component is generally suppressed below $10 \mathrm{~dB}$. Computed peak gain were $-15 \mathrm{dBi}$ and $-18 \mathrm{dBi}$ respectively for the antenna implanted within the small and the large muscle blocks respectively. To put things into perspective the peak gain of the conventional PIFA described before $(14.6 \mathrm{~mm}$ by $10 \mathrm{~mm})$ implanted within the small muscle block was $-10.9 \mathrm{dBi}$. The Hilbert IFA occupies only $11.5 \%$ of the area the conventional PIFA needs. It is clear that none of these antennas will be able to connect to a satellite given their low gain and hence a low noise amplifier will be required. Thus as we mentioned earlier it makes sense that we try to miniaturize the antenna as much as possible.

\section{EXPERIMENTAL RESULTS}

\section{A. VSWR Characteristics}

To ensure biocompatibility the substrate and superstrate must be selected judiciously so that the antenna and all electronics and components can be housed within it. The complete assembly must not cause

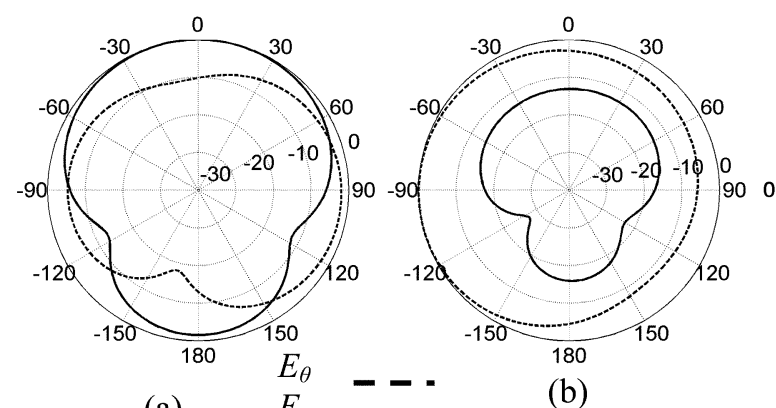

(a)

(b)

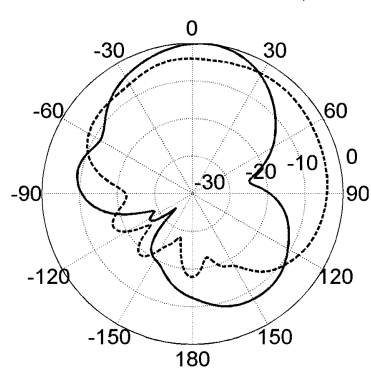

(c)

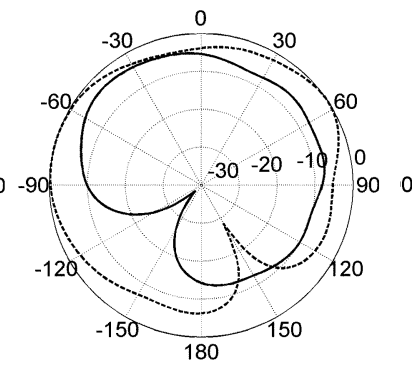

(d)
Fig. 6. Computed normalized radiation patterns of the implanted Hilbert IFA in (a) $x z$ plane $\left(\phi=0^{\circ}\right)$, (b) $y z$ plane $\left(\phi=90^{\circ}\right)$ within small muscle block in XFDTD at $1.585 \mathrm{GHz},(\mathrm{c}) x z$ plane $\left(\phi=0^{\circ}\right)$, (d) $y z$ plane $\left(\phi=90^{\circ}\right)$ in anatomically based human head and body model in XFDTD at $1.635 \mathrm{GHz}$.

any health risk to the person. Therefore, as indicated before we performed simulations of the Hilbert IFA with two biocompatible materials, macor $\left(\varepsilon_{r}=6.1\right)$ and silicone $\left(\varepsilon_{r}=3.1\right)$ as the substrate and superstrate, respectively. However, due to the unavailability of these materials in our lab we decided to look for other materials which have similar dielectric properties as commonly available biocompatible materials for antenna fabrication and testing. We chose to use Duroid 5880 $\left(\varepsilon_{r}=2.2\right.$, loss tangent: $\left.\tan \delta=0.0009\right)$ both as the substrate and superstrate because it has similar properties as the biocompatible material PTFE $\left(\varepsilon_{r}=2.1\right.$, loss tangent: $\left.\tan \delta=0.001\right)$. Since the dielectric constant of the newly selected material is lower compared to that of macor and silicone the antenna dimensions needed to be readjusted in order to achieve resonance at $1.575 \mathrm{GHz}$. The antenna with trace and gap widths of $0.65 \mathrm{~mm}$ was printed on a $0.125 \mathrm{~mm}$ thick Duroid 5880 substrate and then glued on another $3.0 \mathrm{~mm}$ thick Duroid 5880 substrate. The superstrate was $1.6 \mathrm{~mm}$ thick. The overall dimension of the new antenna was $21.45 \mathrm{~mm}$ by $10.095 \mathrm{~mm}$. The antenna was immersed in a tissue simulating liquid which was within a cylindrical plastic container with diameter $60 \mathrm{~mm}$. During measurement, the gaps on all sides between the substrate and superstrate of the antenna was covered with a thin layer of water resist adhesive flexible and stretchable sealant to protect the antenna from being shorted out by the conductive fluid in which it was going to be immersed in. An RG174 cable was used to connect the antenna with a network analyzer cable through a hole created in one of the side walls of the container. The hole was also sealed with the sealant. Muscle tissue equivalent fluid made from distilled or deionized water, sugar and salt was used as the test material which had a dielectric constant of 53.8 and conductivity of $1.4 \mathrm{~S} / \mathrm{m}$ at $1575 \mathrm{MHz}$ [20]. Bactericide which is generally used for the prevention of breakdown was avoided here as this and all the field test measurements done subsequently were performed shortly after making the solution. Note that unlike the simulation model there was no separate liquid in the container to represent the $1 \mathrm{~mm}$ thick skin tissue. The top surface of the antenna was approximately $2 \mathrm{~mm}$ below the muscle equivalent fluid. 


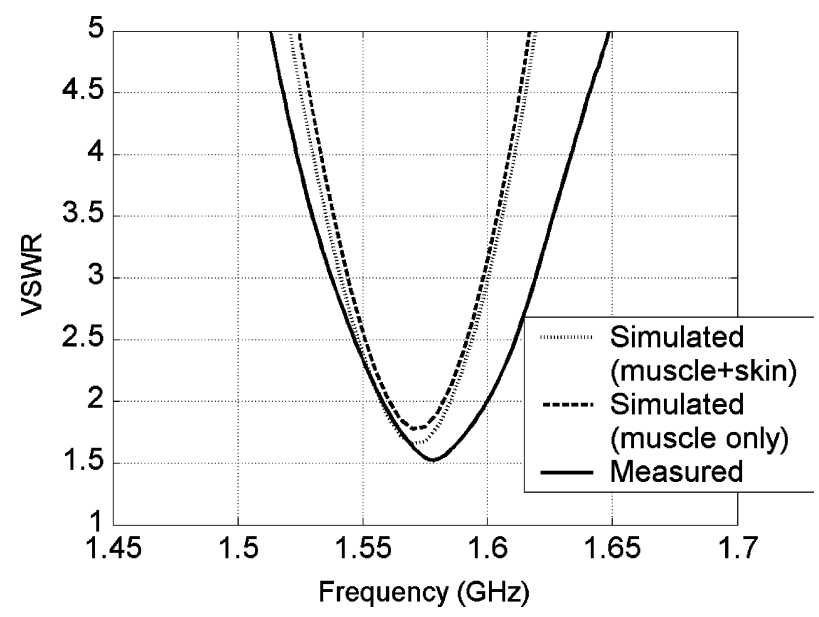

Fig. 7. Simulated and measured VSWR characteristics.

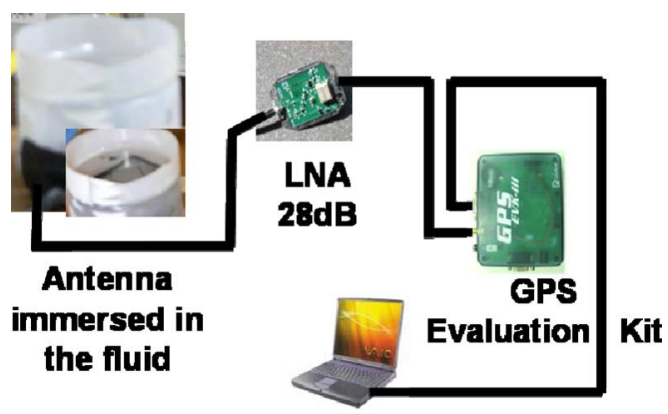

Fig. 8. Field measurement set up.

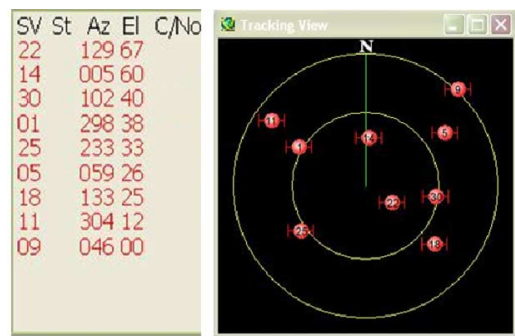

(a)

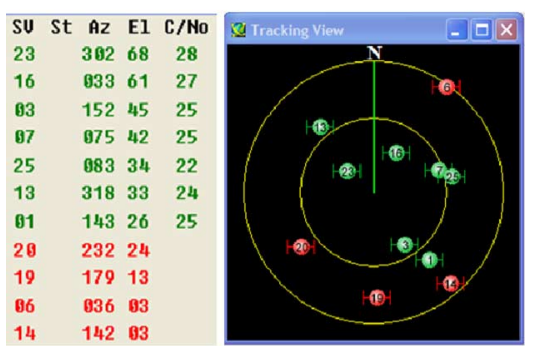

(b)

Fig. 9. Screen shots of the measurement (a) antenna in air and (b) antenna in fluid.

Simulated and measured resonant characteristics of the Hilbert IFA are compared in Fig. 7. The agreement between the computed (using muscle-skin block and muscle block only) and the measured data is good. The measured data demonstrate slightly wider bandwidth (4\%) compared to the simulated data $(3.1 \%)$ which is probably due to the

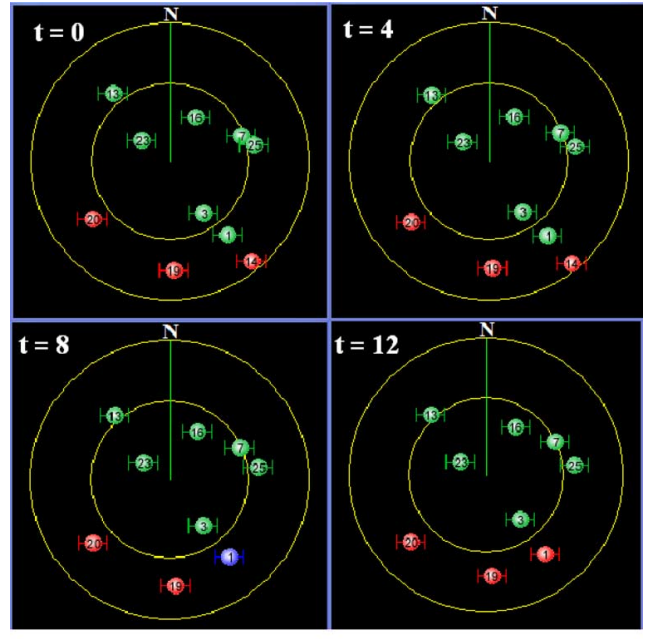

(a)

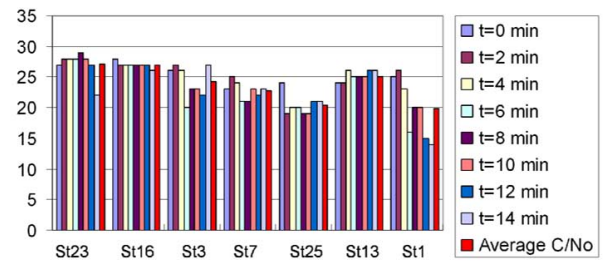

(b)

Fig. 10. (a) Screen shots at 4 min interval and (b) $\mathrm{C} / \mathrm{N}_{\mathrm{o}}$ of seven satellites at 2 min interval

more lossy nature of the liquid used for measurement compared to that of the muscle and skin used for simulation.

\section{B. Field Measurements}

To assess the performance of the GPS antenna implanted inside the human body, live GPS signal measurements were carried out in the open sky. Carrier to noise ratio $\left(\mathrm{C} / \mathrm{N}_{0}{ }^{3}\right)$ and the ability to detect satellites based on field measurements were recorded to evaluate the antenna performance. A SIRF GPS evaluation kit was used for all measurements. This is the main parameter which indicates if the GPS unit will be able to lock into a particular satellite. The field test set up is shown in Fig. 8. The antenna was connected to a $28 \mathrm{~dB}$ gain low noise amplifier (LNA) with the help of an RG 174 coaxial cable. The cable had $1.2 \mathrm{~dB} / \mathrm{m}$ attenuation resulting in a net LNA plus cable gain of $22 \mathrm{~dB}$. The SIRF GPS test kit was interlocked between the LNA and a laptop computer in which the $\mathrm{C} / \mathrm{N}_{\mathrm{O}} \mathrm{S}$ and the number and position of the tracked satellites were recorded. Initially field tests were performed with the GPS Hilbert IFA in air (or in other words, the antenna not immersed in the liquid). Then the antenna was placed within the liquid and new measurements were taken. These results are compared in Fig. 9. As the antenna was designed for operation when implanted within human muscle it could not lock into any satellite when not immersed in the liquid [see Fig. 9(a)].

On the other hand, as can be seen from Fig. 9(b), the GPS antenna immersed in the test fluid along with the GPS receive module was able to lock into seven satellites (green color represents satellites with signal locked). For proper location identification a GPS receive module must lock into at least four satellites. The tracking view screen displays the locations of the satellites. The outer circle represents the

${ }^{3}$ Carrier to Noise ratio $(\mathrm{C} / \mathrm{No})$ is the ratio of the power of the GPS carrier wave $(\mathrm{dBW})$ to the noise power density $(\mathrm{dBw}-\mathrm{Hz})$. 
horizon (Elevation $=0$ degrees), the inner circle represents $45^{\circ}$ elevation, and the center point represents the direction directly overhead (Elevation $=90$ degrees). The symbols $A z$ and $E l$ represent the azimuth and elevation locations of the satellites, respectively. The vertical straight line towards $N$ represents the 0 degree angle for the azimuth plane. For example, by moving $83^{\circ}$ from this reference line in the azimuth plane and then $34^{\circ}$ in the elevation plane we can track satellite \#25. Signals from satellites \#23, \#16, \#3, \#7, \#25, \#13 and \#1 can be used for navigation purpose (these are represented by the small green spheres with the satellite number inscribed inside each sphere). $\mathrm{C} / \mathrm{N}_{\mathrm{o}}$ of these useful satellite signals at that instant are 28, 27, 25, 25, 22, 24, $25 \mathrm{dBHz}$ respectively.

Next, field measurements were performed at 2 min time intervals. Fig. 10(a) shows the position and number of useful satellites at $4 \mathrm{~min}$ time intervals. From Fig. 10(a) it is clear that for up to $t=4 \mathrm{~min}$ there are seven satellites locked with the GPS receiver. But as time progressed to $t=8 \mathrm{~min}$ the color of satelitte \#1 became blue from green indicating low signal level. At $t=12 \mathrm{~min}$ the circle became red indicating loss of connection. Fig. 10(b) further elucidates the above observation in terms of the measured $\mathrm{C} / \mathrm{N}_{\circ}$ value of each individual satellite. Clearly the $\mathrm{C} / \mathrm{N}_{0}$ of satellite \#1 decreased to a very low value of less than $15 \mathrm{~dB}$ when $\mathrm{t}=12 \mathrm{~min}$. The average $\mathrm{C} / \mathrm{N}_{\text {o values for }}$ satellites \#23,\#16, \#3,\#7, \#25, \#13 and \#1 are 27.12, 27, 24.25, 22.75, 20.38, 25.12, $19.87 \mathrm{dBHz}$ respectively.

\section{CONCLUSION}

The study and design of a miniature Hilbert inverted-F antenna is presented for implantable GPS application. The idea is to implant the antenna under the shoulder skin of the elderly with declining mental capacity, such as Alzheimer's patient to track their locations when they may stray away from a care giving facility. A detailed study of the antenna along with the effect of the substrate and superstrate materials is presented. Analyses data are presented both in the case of a block muscle plus skin model as well as with an anatomically based human head and body model. The antenna performs well within both models. The resonant characteristics of the antenna are described and the ways to mitigate the potential frequency sensitivity as function of the substrate and superstrate materials and their thicknesses are addressed. A prototype antenna is fabricated and tested for VSWR performance by immersing the antenna in a tissue simulating liquid. Finally GPS field tests are performed with the help of an LNA and an evaluation kit to demonstrate performance.

\section{REFERENCES}

[1] Z. Gu, C. Rappaport, P. Wang, and B. VanderBrink, "Development and experimental verification of the wide-aperture catheter-based microwave cardiac ablation antenna," IEEE Trans. Microw. Theory Tech., vol. 48, pp. 1892-1900, Nov. 2000.

[2] P. Soontornpipit, C. M. Furse, and Y. C. Chung, "Design of implantable microstrip antenna for communication with medical implants," IEEE Trans. Microw.. Theory Tech., vol. 52, pp. 1944-1951, Aug. 2004.

[3] K. Gosalia, G. Lazzi, and M. Humayun, "Investigation of a microwave data telemetry link for a retinal prosthesis," IEEE Trans. Microw. Theory Tech., vol. 52, pp. 1925-1933, Aug. 2004.

[4] A. Guy, J. F. Lehman, and J. B. Stonebridge, "Therapeutic applications of electromagnetic power," Proc. IEEE, vol. 62, pp. 55-75, Jan. 1974.

[5] [Online]. Available: http://www.verimedinfo.com

[6] [Online]. Available: www.digitalangelcorp.com/about_pressreleases. asp?RELEASE_ID $=240$

[7] M. Z. Azad and M. Ali, "A miniaturized implantable antenna for GPS application," in IEEE Antennas and Propag. Society Int. Symp. Digest, 2006, pp. 1103-1106.

[8] N. Padros, I. Ortigosa, J. Baker, F. Iskander, and B. Thornberg, "Comparative studies of high-performance GPS receiving antenna designs," IEEE Trans. Antennas Propag., vol. 45, pp. 698-706, Apr. 1997.

[9] J. M. Tranquilla and S. R. Best, "A study of the quadrifilar helix antenna for global positioning system applications," IEEE Trans. Antennas Propag., vol. 38, pp. 1545-1550, Oct. 1990.

[10] L. Boccia, G. Amendola, and G. Di Massa, "A dual frequency microstrip patch antenna for high precision GPS application," IEEE Antennas Wireless Propag. Lett., vol. 3, pp. 157-160, 2004.

[11] H. Tseng and Y. L. Chiu, "A compact size microstrip antenna for GPS application," Microw. Opt. Technol. Lett., vol. 48, no. 4, pp. 810-814, Apr. 2006.

[12] K. Oh, B. Kim, and J. Choi, "Novel integrated GPS/RKES/PCS antenna for vehicular application," IEEE Microw. Wireless Comp. Lett., vol. 15, no. 4, pp. 244-246, Apr. 2005.

[13] J. Zhu, A. Hoorfar, and N. Engheta, "Bandwidth, cross-polarization, and feed-point characteristics of matched Hilbert antennas," IEEE Antennas Wireless Propag. Lett., vol. 2, pp. 2-4, 2003.

[14] X. Chen, S. Naeini, and Y. Liu, "A down-sized printed Hilbert antennas for UHF band," in Proc. IEEE Antennas Propag. Society Int. Symp. Dig., 2003, vol. 2, pp. 581-584.

[15] M. Z. Azad and M. Ali, "A miniaturized Hilbert PIFA for dual-band mobile wireless applications," IEEE Antennas Wireless Propag. Lett., vol. 4, pp. 59-62, 2005.

[16] M. Z. Azad and M. Ali, "A new class of miniature embedded inverted-F antennas (IFAs) for $2.4 \mathrm{GHz}$ WLAN application," IEEE Trans. Antennas Propag., vol. 54, pp. 2585-2592, Sep. 2006.

[17] [Online]. Available: http://www.fcc.gov/cgi-bin/dielec.sh

[18] J. Kim and Y. Rahmat-Samii, "Implanted antennas inside a human body: Simulations, designs, and characterizations," IEEE Trans. Microw. Theory Tech., vol. 52, pp. 1934-1943, Aug. 2004.

[19] ITIS Foundation, [Online]. Available: www.Itis.ethz.ch, Zurich, Switzerland

[20] M. Y. Kanda, M. Ballen, S. Salins, C. K. Chou, and Q. Balzano, "Formulation and characterization of tissue equivalent liquids used for RF densitometry and dosimetry measurements," IEEE Trans. Microw. Theory Tech., vol. 52. 